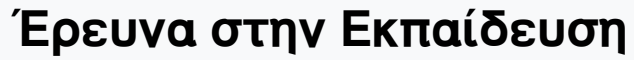

Tóp. 6, Ap. 2 (2017)

Special Issue: Lesson Study - A Scientific Meeting for Exchanging Views and Exploring the Model Across Europe

Special Issue dedicated to the Scientific Symposium with International Participation: Lesson Study: A Scientific Meeting for Exchanging Views and Exploring the Model Across Europe, Alexandroupolis, 7 and 8 March 2017
Pilot implementation of a participatory Lesson Study model in assessing an educational toy design workshop in a museum: preliminary results

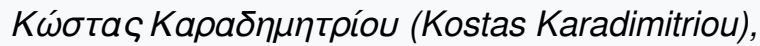
Katerina Gioftsali, Myrsini Lantzouraki, Maria Moumoulidou, Galini Rekalidou

doi: $\underline{10.12681 / \text { hire.14869 }}$

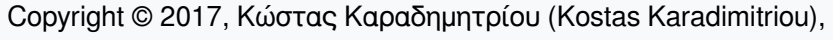
Katerina Gioftsali, Myrsini Lantzouraki, Maria Moumoulidou, Galini Rekalidou

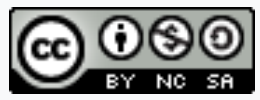

Alexandroupolis, 2017

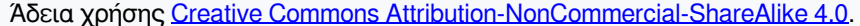

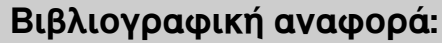

Kapaঠ̄nuntpíou (Kostas Karadimitriou) K., Gioftsali, K., Lantzouraki, M., Moumoulidou, M., \& Rekalidou, G. (2017). Pilot implementation of a participatory Lesson Study model in assessing an educational toy design workshop in a museum: preliminary results. 'E 


\title{
Pilot implementation of a participatory Lesson Study model in assessing an educational toy design workshop in a museum: preliminary results
}

\author{
Karadimitriou K., Gioftsali K., Lantzouraki M., Moumoulidou M., Rekalidou G. \\ Department of Education Sciences in Early Childhood, Democritus University of Thrace
}

\begin{abstract}
The present study is structured on two levels and is conducted by the interdisciplinary collaboration of five researchers (a Museologist, three Pedagogists and a Theatre-educator). The first level concerns the pilot implementation of a one-day workshop for postgraduate students to produce educational toys in an informal setting (a museum). The second level of the study concerns the assessment of the workshop instruction in relation to its effectiveness in the production of educational toys by the students within the context of the museum as well as the improvement of the researchers teaching practices and professional development. For this purpose, we used the Lesson Study model (LS), but to evaluate the effectiveness of the workshop we decided to actively involve the group of the postgraduate students in the reflection process of the workshop debriefing session by proposing a participatory approach. The analysis of the data is in progress and is expected to bring out valuable information concerning the effectiveness of our teaching practices and the improvement of the workshop for future applications in museum settings. Similarly, it is expected to highlight options in postgraduate students learning experience, such as acquired knowledge, innovation and creativity by using museum objects to create educational toys, as well as social skills like collaboration and evidence of enjoyment. So far, we present our methodology, the workshop structure and preliminary thoughts and results concerning the workshop assessment.
\end{abstract}

(c) 2017, Karadimitriou K., Gioftsali K., Lantzouraki M., Moumoulidou M., Rekalidou G.

Keywords: lesson study; informal learning; adult learning; teaching assessment; professional development of academic staff

\section{Introduction}

This project concerns the implementation of a workshop for producing educational toys in the Ethnological Museum of Thrace - Greece (http://emthrace.org) and its assessment with the Lesson Study Model (LS). The workshop was addressed to the postgraduate students of the course "Innovative Pedagogical Approaches in Multi - Cultural Educational Environments" of the Department of Education Sciences in Preschool Education of the Democritus University of Thrace (http://mcultural.gr) and was attended voluntary by six of them.

The above course aims to provide postgraduate teaching, research and practical application in the academic fields of Intercultural Education as well as of the Informal, Non-Formal and Formal Education of children, teenagers and adults. 
The motive of the five contributors (a Museologist, three Pedagogists and a Theatre-educator) as teachers of the above course was on one hand to improve their teaching practices and on the other to offer the postgraduate students an alternative and innovative educational experience. Therefore, the purpose of the project was:

a) The students to acquire the essential knowledge and skills to design and create, in small groups, their own educational toys inspired by the museum objects and incorporate them into the museum context, taking into account the special characteristics of the informal learning settings and in particular the museum and its public.

b) The assessment of the workshop instruction in relation to its effectiveness in producing educational toys by the students in the context of the museum and the assessment of students` learning experience as well.

c) The improvement of the five contributors` teaching practices / professional development.

\section{A Participatory approach in Lesson Study model}

The postgraduate students who attended the workshop were all adult learners coming from different academic fields and bringing to the postgraduate course preconceived thoughts and feelings. Adult learning according to Knowles (1980) is a process of self-directed inquiry and the reason most adults enter any learning experience is to create change. This could encompass a change in their skills, behavior, knowledge level and their attitudes about things (Russell 2006:349).

Literature review on adult learning reveals a range of common characteristics among adult learners. First of all they learn effectively only when they have a strong inner motivation (Knowles 1984:12 in Smith, M., 2002) to develop a new skill or acquire a particular type of knowledge. They are also in a continual process of learning (formal, non-formal and informal) while developing their own preferred style of learning that suits them the most (Rogers, 1999:92, Kokkos 2005). Another common characteristic is that they have a range of background knowledge, a set of experiences that become an increasing resource for learning (Knowles 1984:12 in Smith, M., 2002) validating the information from their own values and attitudes (Rogers, 1999:92, Knowles 1984). Furthermore, adult learners need to decide for themselves what is important to learn because according to Knowles (1950:44) they are goal oriented and become ready to learn when "they experience a need to learn in order to cope more satisfyingly with real- life tasks or problems". As skills and knowledge are acquired by the learner, emphasis must be given to skills that learners can apply to real-life situations and not to abstract concepts (Kokkos, 2005, Russell 2006). Finally, they have a tendency for active participation and expect to be actively involved in the planning and evaluation of the learning process (Knowles 1984, Kokkos 2005, Kearsley 2010).

A question that arises from the above is whether the basic approach of the Lesson Study model can capture the complexity of the learning process of the post-graduate students' (adult learners) experience. Lesson Study focuses on the modification of personal theories of teachers in relation to the implementation of educational practices and to the general improvement of their teaching practices as well as on building knowledge of how students learn. In LS, teachers base the lesson design on their ideas on how students learn, observe student learning when the lesson is taught, analyze observations of student learning after the lesson is taught and use information about student learning to revise the lesson. All the above include lesson study team's perceptions neglecting students' perspective on their learning experience. Specifically, the observers of students during the lesson cannot capture holistically the complexity of the learning process which students experience because they are not able to search inside the individual, to gain insight into the cognitive and emotional aspect of learning. As Eilean Hooper-Greenhill states (1999:21): 
"learning involves a great many processes. The most basic ones are perception and memory [....] learning is influenced by motivation and attitudes, by prior experiences, by culture and background, and especially in museums - by design and the physical setting. Learning includes acquisition of facts and knowledge, but also experiences and emotions. It requires individual efforts, but it is also a social experience".

Furthermore, the UK Campaign for Learning ${ }^{1}$ identifies that:

"learning is a process of active engagement with experience, it is what people do when they want to make sense of the world. It may involve the development or deepening of skills, knowledge, understanding, values, ideas and feelings or an increase in the capacity to reflect. Effective learning leads to change, development and the desire to learn more" (Hooper Greenhill et al, 2003:9).

The above definition of learning has direct implications for the methods used to gain insights into the process of learning and also underpins our desire to include a participative approach (Wood \& Cajkler 2016). In particular, we decided to actively involve the participants (group of the postgraduate students) in the reflectivity process of the post-lesson (workshop) review session and jointly discuss their possible learning outcomes from the instruction of the workshop.

Thus, the inclusion of postgraduate students in the debriefing session of this project gave the opportunity to:

a) Focus on the use of a modified approach to lesson study which aims to help the academic staff gaining an explicit understanding of student learning as well as which elements in their learning they believe are important for them to take further at a given point in time.

b) Consider ways in which postgraduate students can be engaged as active participants within a lesson study framework in order to aid in the understanding of learning challenges of the workshop and their possible solutions.

\section{Methodology}

We decided to use the Lesson Study model (LS), which is characterized by the elements of cooperation, reflection and feedback (Rekalidou, Karadimitriou, Moumoulidou, 2014) and focuses on the modification of personal theories of teachers both in relation to the implementation of educational practices and the general improvement of their teaching practices (Marble, 2007). But, as described earlier, in attempting to base data collection on a more critical foundation regarding the complexity of the learning process and outcomes, by gaining insights into students' learning, as well as to evaluate the effectiveness of the workshop, we have come to the conclusion that the use of a participatory approach in the cycle of the LS model is essential.

The methodological framework we used represents a holistic approach to learning where learning is a dynamic process of meaning making dependant on both the individual and their environment that focuses on some change. To this end, the methodology used was qualitative in nature following the Generic Learning Outcomes (GLOs) ${ }^{2}$ approach to "measuring learning". According to this approach

\footnotetext{
${ }^{1}$ See: http://www.campaign for learning.org.uk/cfl/yourlearning/why_is_learning_important.asp

${ }^{2}$ Generic Learning Outcomes model was developed as a tool for museums, libraries and archives todemonstrate the outcomes and impact of users' learning experiences (see: University of Leicester, The Generic Learning Outc omes Measuring Learning Impact in Museums) see http://www.artscouncil.org.uk/measuring-outcomes/genericlearning-outcomes
} 
Hellenic Journal of Research in Education, Special Issue dedicated to the Scientific Symposium with International Participation: Lesson Study: A Scientific Meeting for Exchanging Views and Exploring the Model Across Europe, Alexandroupolis, 7 and 8 March 2017

five generic learning outcomes are proposed: 1) increase in knowledge and understanding, 2) increase in skills, 3) change in attitudes or values, 4) evidence of enjoyment inspiration and creativity, 5) evidence of activity, behaviour, and progression (Hooper-Greenhill et all 2003). Taking the discussion between the students and the researchers' team as the primary data source of their learning experiences we utilized three of the five categories of the GLOs which best suited to the nature of our research: increase in knowledge and understanding; increase in skills and evidence of creativity, inspiration and enjoyment. These three categories served as the theoretical framework for the interpretation of the results concerning the "learning" parameter in the first three workshop assessment questions (AQ):

AQ1: Did students manage to integrate elements of learning on how to design and produce educational toys in the museum setting? What are these elements and how did they integrate them?

AQ2: Which of the above elements are relevant to the following three categories of the GLOs model? a) Knowledge and Understanding $[\mathrm{K} ; \mathrm{U}]$, b) Skills $[\mathrm{S}]$, c) Enjoyment, Inspiration and Creativity $[\mathrm{E} ; \mathrm{I} ; \mathrm{C}]$

AQ3: Are there any elements that have been taught in the workshop but are not exploited by the students? What are these; What are the possible explanations for this?

The fourth workshop assessment question mainly focuses to the organization of the teaching:

AQ4: What difficulties for the students or any other deficiencies were observed, both in the theoretical and empirical part of the workshop? To what extent is the organization of the teaching related to all the above?

Data for the workshop assessment were mainly collected via video recordings (the whole procedures were video recorded). Observation notes were also kept from one researcher during the implementation of the workshop. The final participatory feedback/reflection session, which is our main data resource, was very flexible because even though there was a list of questions to be covered, many questions and topics that were not included in the guide emerged as the instructors followed up the students' replies. However, there was a general plan which was followed. Prompts were used either as examples for respondents or to encourage them to expand on any points. Researchers` and students` comments from the feedback/reflection sessions, observation notes and the other data from the workshop implementation will be triangulated in order to present the results of the assessment in a forthcoming paper.

\section{The structure of the workshop}

The workshop was structured following three steps:

A. First step: The LS team after brainstorming sessions:

- defined and divided roles between the members of the team: teaching and observing

- decided upon the selection criteria of the participants: six postgraduate students

- chose the setting: Ethnological Museum of Thrace

- defined the theoretical approach of play, educational play and play in the museum

- decided about the teaching approach: lecture and practical activities

- $\quad$ selected the toy design model: the "Play Pyramid" (Kudrowitz \& Wallace, 2009)

- planned the workshop in every other detail: materials, duration, etc.

B. Second step: a) implementation and observation of the workshop b) first participatory feedback/reflection session 
Hellenic Journal of Research in Education, Special Issue dedicated to the Scientific Symposium with International Participation: Lesson Study: A Scientific Meeting for Exchanging Views and Exploring the Model Across Europe, Alexandroupolis, 7 and 8 March 2017

The workshop instruction was developed as follows:

$>$ 10:00-11:00: guided tour for the students in the museum

> 11:00-13.30: workshop implementation (three of the researchers implemented the instruction while the two others observed and recorded data, one using a video camera and the other taking notes)

$>$ 13.30-14.00: break

$>$ 14:00-15:00: preliminary brainstorming session by the students in order to discuss about their educational toy (instructors supported where needed)

> 15:00-16:00: first participatory feedback/reflection session: LS team and students discussed and assessed the workshop

The issues that were discussed were the strong and weak points of the workshop, the improvement of the content of the workshop, the implemented teaching practices and the learning experience for the students.

C. Third step: a) presentation of the students educational toy in the museum b) final participatory feedback/reflection session and revision ${ }^{3}$

Students formed one team, worked on their own and after a week they presented their educational toy in the museum and gave the researchers the chance to test it (play with it). Another in depth feedback/reflection session with the active participation of the students followed in order to assess the whole workshop.

\section{Preliminary thoughts and expected outcomes from the research}

The following ascertainments present our perspective, as observers and instructors on the assessment of the workshop instruction and the students learning experience. The upcoming analysis of the video recordings and observation notes will help us to re - evaluate them in a more holistic way.

Concerning the first two assessment questions we observed that students managed to integrate all the fundamental elements of the workshop instruction on how to design and produce educational toys in the museum setting and have been engaged in the three categories of the GLOs model. More or less the learning outcomes for the students are described simultaneously by all three categories because of the nature and the theme of the project on the one hand and the organization of the teaching on the other which combined theory and praxis and required from the students to implement knowledge and understanding $[\mathrm{K} ; \mathrm{U}]$ and skills $[\mathrm{S}]$ in order to create an enjoyable experience (play) $[\mathrm{E} ; \mathrm{I} ; \mathrm{C}]$ not only for themselves but also for the players of their toy.

More precisely, we noticed that the empirical part of the workshop inspired students` toy design (e.g. they incorporated movement, pantomime and visual arts). Theory was also well integrated in it. For example, based on the "Play Pyramid" model they managed to give multifaceted play value to their toy (elements of sensory, fantasy, construction and challenge) and they incorporated characteristics of "play" in their toy based on knowledge acquired in the workshop (the dimension of pretence, freedom of choice, the rules, elements of pleasure and fun). In addition, they used museum objects appropriately for creating personal meanings to players (e.g. a task for reflection with museum objects) and they set educational objectives on each task of their toy and a pedagogical perspective as

\footnotetext{
${ }^{3}$ Revision is going to be implemented after the analysis of the data.
} 
well (e.g. cultivation of skills, acquiring specific knowledge, interaction between parents and children/adults-children etc.). Concerning workshop's theory, they also integrated the theory of Zone of Proximal Development (ZPD) and tried to balance the skills from the players needed with the toy requirements (tasks for interaction between adults and children, tasks with multiple levels of difficulty). Finally, they enriched the developmental value of their toy through players' interaction and with the stabilization of recently acquired knowledge from the guided tour in the museum (e.g. cooperative tasks, tasks of recalling information from the museum, implementation of new knowledge acquired from the museum collections).

Regarding the third assessment question we noticed that all the elements that have been taught in the workshop were exploited by the students. The first feedback session and the experiential activities after every theoretical module helped the students to recall theory and implement it.

Concerning the fourth assessment question, we noticed that students released themselves very slowly during the first experiential activity and only those who had previous experience acted more freely from the beginning. There was an improvement for all in the next one. This is probably due to the fact that the first experiential activity began abruptly. We suggest adding more time of free movement and familiarization with the museum during the motivation part of the activity in future applications.

We also observed that students were attached to the knowledge acquired by the guided tour in the museum and that was obvious from the way they managed the declarative knowledge in their toy (there were many close ended questions for the players to answer). We suggest adding a more intuitive introductory part of engagement with the museum's exhibits (e.g. through a game) in future applications. In addition, we would proportionally expect more open ended than close ended tasks in their toy (e.g. more fantasy and creative play), which is more desirable in the informal education context. Probably their previous experience as students in the formal Education System contributed to that outcome and also the fact that we did not teach a module about the types of the play materials (open/close ended) and their possible uses in activities. The latter is going to be added in the workshops content for future applications.

This interdisciplinary project offered to the researchers the opportunity to collaborate, exchange points of view and learn from each other. In addition every member of the LS team was interested in the results of the assessment and the improvement of this workshop as a whole and also on its parts, especially in relevance to their special area of interest. On that basis, the whole procedure and its outcomes served as a mean of professional development.

We also found LS model to be effective in the informal education context since our experiences, as researchers, were restricted to formal education settings (preschool classes).

The perspective of empirical learning also proved to fit perfectly to the context of the museum and offered a full enjoyable experience to the students, which is the quest for informal education. Students` comments during the first participatory feedback session (see: second step in the "structure of the workshop instruction" section of this paper) revealed their feelings of enjoyment and that they most liked the combination of theory and praxis. Video recording analysis will help us deepen our understanding on the engagement elements of the workshop.

We intent to examine all the unrefined data of this project in order to re - evaluate the above preliminary thoughts and enlighten the learning outcomes from this workshop for the students, point out more pros and cons of our teaching practices and improve the workshop for future applications in the museum setting. 
Hellenic Journal of Research in Education, Special Issue dedicated to the Scientific Symposium with International Participation: Lesson Study: A Scientific Meeting for Exchanging Views and Exploring the Model Across Europe, Alexandroupolis, 7 and 8 March 2017

\section{References}

Hooper-Greenhill, E., Dodd, J., Moussouri, T., Jones, C., Pickford , C., Herman, c., Morrison, M., Vincent, J., \& Toon, R. (2003). Measuring the Outcomes and Impact of learning in Museums Archives and Libraries. Retrieved from

https://www2.le.ac.uk/departments/museumstudies/rcmg/projects/lirp-12/LIRP\%20end\%20of\%20project\%20paper.pdf

Hooper-Greenhill, E. (1999). Education, communication and interpretation: towards a critical pedagogy in museums. In Hooper-Greenhill, E. (Ed.), $\left(2^{\text {nd }}\right.$ ed.) The Educational Role of the Museum (pp.3-27). London: Routledge.

Kearsley, G. (2010). Andragogy (M.Knowles). The theory into practice database. Retrieved from http://tip.psychology.org

Knowles, M. (1984). Andragogy in action. San Francisco, SA: Jossey- Bass.

Kokkos, A. (2005). Adult learning. Investigating the domain. Athens: Metaixmio [in Greek]

Kudrowitz, B. M., \& Wallace, D. R. (2009). The play pyramid: A play classification and ideation tool for toy design. International Journal of Arts and Technology, 3(1), 36-56.

Marble, S. (2007). Inquiring into teaching: Lesson study in elementary science methods. Journal of Science Teacher Education, 18(6), 935-953.

Rekalidou G., Karadimitriou K., \& Moumoulidou M. (2014). Application of Lesson Study with students. Collaboration, reflection and feedback. Hellenic Journal of Research in Education, 1, (3), 528. doi:10.12681/hjre.8935 [in Greek]

Rogers, A. (1999). Adult education. Athens: Metaixmio. [in Greek]

Russell, S. (2006). An overview of adult learning processes. Urologic Nursing, 26(5), 349-352.

Smith, M. K. (2002). Malcolm Knowles, informal adult education, self-direction and andragogy. The encyclopedia of informal education. Retrieved from www.infed.org/thinkers/et-knowl.htm.

Wood, P \& Cajkler, W. (2016). A participatory approach to Lesson Study in higher education. International Journal for Lesson and Learning Studies, 1, (5), 4-18. https:// doi.org/10.1108/IJLLS08-2015-0027

\section{Web pages:}

Ethnological Museum of Thrace - Greece. Retrieved from http://emthrace.org

Postgraduate Course "Innovative Pedagogical Approaches in Multi - Cultural Educational Environments". Department of Education Sciences in Preschool Education, Democritus University of Thrace. Retrieved from http://mcultural.gr

The Generic Learning Outcomes, Measuring Learning Impact in Museums. Retrieved from http://www.artscouncil.org.uk/measuring-outcomes/generic-learning-outcomes 